\title{
Sobre a narrativa como categoria analítica da avaliação escolar
}

\author{
Lívia Suassuna \\ Universidade Federal de Pernambuco
}

\section{Resumo}

Neste estudo, discutimos a prática da avaliação no campo da linguagem. Na primeira parte, mostramos os limites das práticas avaliativas centradas numa concepção de linguagem como estrutura e de avaliação como mensuração. $\mathrm{Na}$ segunda, expomos algumas ideias do autor em cujo pensamento nos baseamos para a reconceptualização da avaliação; trata-se de Walter Benjamin, especificamente do livro Magia e técnica, arte e política - ensaios sobre literatura e história da cultura. Na terceira, mostramos como o processo de ensino pode ser entendido como narrativa e o professor, como um narrador, na perspectiva da avaliação enquanto ação discursiva a serviço da aprendizagem e da qualidade da educação.

Palavras-chave: Avaliação. Ensino. Aprendizagem. Linguagem - avaliação. 


\section{Narratives as an analytical category of school evaluation}

In this study we discuss evaluation practices in the field of language studies. In the first part, we show the limits of traditional evaluating practices, centered in a conception of language as structure and of evaluation as measurement. In the second one, we show some ideas of the author upon whose thought we based our new concept of evaluation; Walter Benjamin, specifically in the book Magic and technique, art and politics - essays on literature and culture history. In the third part, we show how the teaching process can be understood as a narrative and the teacher as a narrator, in the perspective of evaluation as discursive action, at the service of the learning process and the quality of education.

Keywords: Evaluation. Teaching. Learning. Language- evaluation.

\section{Sobre la narrativa como categoría analítica de la evaluación escolar}

En este estudio, discutimos la práctica de la evaluación en el campo del lenguaje. En la primera parte, mostramos los límites de las prácticas evaluativas centradas en una concepción de lenguaje como estructura y de evaluación como mensuración. En la segunda, exponemos algunas ideas del autor en cuyo pensamiento nos basamos para la reconceptualización de la evaluación; se trata de Walter Benjamin, específicamente, en el libro Magia y técnica, arte y política - ensayos sobre literatura e historia de la cultura. En la tercera, mostramos cómo el proceso de enseñanza puede ser entendido como narrativa y el profesor, como un narrador, en la perspectiva de la evaluación como acción discursiva a servicio del aprendizaje y de la calidad de la educación.

Palabras-clave: Evaluación. Ensenãnza. Aprendizaje. Lenguaje-evaluación. 


\section{Sobre a narrativa como categoria analítica da avaliação escolar}

A questão não é que, a princípio, não saibamos algo e, no final, já o saibamos. Não se trata de uma relação exterior com aquilo que se aprende, na qual o aprender deixa o sujeito imodificado. Aí se trata mais de se constituir de uma determinada maneira. De uma experiência em que alguém, a princípio, era de uma maneira, ou não era nada, pura indeterminação e, ao final, converteu-se em outra coisa. Trata-se de uma relação interior com a matéria de estudo, de uma experiência com a matéria de estudo, na qual o aprender forma ou transforma o sujeito. Na formação humanística, como na experiência estética, a relação com a matéria de estudo é de tal natureza que, nela, alguém se volta para si mesmo, alguém é levado para si mesmo. E isso não é feito por imitação, mas por algo assim como por ressonância. Porque se alguém lê ou escuta ou olha com o coração aberto, aquilo que lê, escuta ou olha ressoa nele; ressoa no silêncio que é ele, e assim o silêncio penetrado pela forma se faz fecundo. (Jorge Larrosa, 2000).

\section{A avaliação escolar - algumas questões}

Ao longo das três últimas décadas, começaram a ganhar corpo, em todo o Brasil, os debates acerca da qualidade do ensino e de suas formas de controle, sobretudo em se tratando de redes públicas. Consolidaram-se, assim, diferentes programas e políticas de avaliação de escolas e/ou redes de ensino, que vieram se somar à tradicional avaliação da aprendizagem, quase sempre centrada no desempenho individual do aluno.

Muitos estudos contemporâneos no campo da educação têm focalizado essas práticas avaliativas que se dão tanto dentro quanto fora da sala de aula. Na verdade, o tema da avaliação e seus resultados enquadra-se numa discussão mais ampla, precisamente aquela que problematiza os paradigmas clássicos da educação e tenta rever verdades iluministas que sempre nos pareceram tranquilas e naturais, como as do sujeito fundante, da razão transcendental e do homem natural e universal (Veiga-Neto, 1994).

Isso porque a ciência clássica, a despeito de seus notáveis avanços e descobertas, não impediu, por exemplo, o fenômeno do fracasso escolar, expresso em altas taxas de evasão e repetência, sobretudo na escola pública brasileira. Historicamente, aliás, a avaliação tem funcionado como mecanismo legitimador desse fracasso: seleciona, de modo unilateral e coercitivo, os "melhores" alunos e exclui, por extensão, aqueles considerados “inaptos”, naturalizando o processo de exclusão social. Essa seletividade do sistema de ensino acaba por definir como legítimos certos conhecimentos, discursos e práticas sociais, em detrimento de outros. 0 erro é absolutizado; a fala dissonante, desprezada. A busca e a valorização da forma correta, adequada, esperada, tornam o currículo um bloco estático e 
padronizado de informações (Esteban, 2000).

Deacon e Parker (1994), remetendo às ideias de Michel Foucault expostas em Vigiar e punir, mostram o caráter disciplinador do exame. Este funcionaria como uma espécie de instrumento pelo qual se sujeita aquele que é percebido como objeto e se objetifica aquele que é sujeitado. Os autores também dizem que o exame, com seus mecanismos associados de julgamento e classificação, determina uma padronização dos resultados, minimizando as características particulares dos sujeitos sob observação ou análise. É como se a história prévia e a singularidade de cada aluno não fossem elementos fundamentais em sua avaliação.

Sarmento et al (1997), em estudo sobre as práticas avaliativas de três escolas diferentes, puderam observar, a despeito de certas particularidades, pontos comuns entre elas. Desses pontos, destacamos alguns que nos pareceram relevantes:

a) a avaliação constitui-se num "ritual impresso na rotina dos alunos"; as atividades, previamente estabelecidas pelas professoras, são distribuídas no tempo escolar de modo invariável;

b) a correção das tarefas é feita de forma mecânica, sem retorno para o aluno quanto ao tipo de erro que ele tenha cometido;

c) o erro é visto como responsabilidade do aluno e é sistematicamente atribuído à falta de atenção;

d) não há preocupação com os interesses, motivações e dificuldades dos alunos; as tarefas são propostas ou interrompidas de modo brusco, sem critério aparente;

e) as tarefas são apresentadas como um dever a cumprir, sem diálogos ou questionamentos, e têm o papel de manter as crianças ocupadas durante todo o tempo;

f) são constantes as ameaças de castigo ou privação; a avaliação, nesse sentido, funciona como um recurso para manter a ordem, na medida em que se explicita constantemente a relação entre ela e a possibilidade de aprovação ou reprovação do aluno;

g) as professoras valorizam aspectos secundários do desempenho dos alunos, tais como letra bonita, caderno limpo, capricho, etc.;

h) as provas são o instrumento preferencial de avaliação e enfatiza-se a nota como um dado em si mesmo;

i) nos exames, os alunos devem repetir o que foi ensinado, restando pouco ou quase nenhum espaço para a criatividade;

j) a avaliação é encarada como uma atividade rotineira e burocrática, e não como parte integrante ou necessidade intrínseca do processo ensino-aprendizagem.

Tendo-se utilizado de diversos materiais de análise - entre eles regimentos das escolas e depoimentos de professoras, diretoras e supervisoras -, Sarmento et al 
constataram um significativo desnível entre a prática avaliativa e os discursos sobre a avaliação. Com efeito, embora nestes se fale da importância do desenvolvimento cognitivo do aluno, naquela a ênfase recai sobre seu comportamento e conduta.

$\mathrm{Na}$ conclusão do trabalho, os autores dizem que as práticas observadas ilustravam uma avaliação repetitiva, acrítica, fragmentária, classificatória, disciplinar, que tem servido ao controle social do corpo discente (via poder de ameaçal, sem que sejam consideradas as raízes sociais do fracasso escolar ${ }^{1}$. Poderíamos, ainda, acrescentar que a avaliação, via de regra, é centrada nos produtos da aprendizagem (em prejuízo dos processos) e tem servido ao processo de "domesticação" dos alunos, enquadrando-os no modelo vigente de sociedade.

Vejamos agora como essas questões se colocam no nosso campo específico de investigação, que é o ensino de língua materna. Podemos dizer que a avaliação não se configura, efetivamente, como um processo dialógico, reduzindo-se, muitas vezes, à mera aferição do conhecimento metalinguístico acabado (nomenclaturas e classificações), ou à verificação de erros presentes na superfície textual (quando se trata da produção escrita), ou, ainda, à capacidade de reprodução de informações explícitas no texto (quando se trata da leitura). Esse procedimento remonta à própria origem do ensino de português, que sempre foi pautado nas gramáticas normativas tradicionais, nas quais a língua é descrita como um código estático e acabado, exterior aos sujeitos e descolado dos contextos de uso.

Partindo da conceituação da gramática como "a arte de bem falar e escrever", os gramáticos sempre estiveram preocupados em estabelecer um modelo de uso da língua. Com poucas variações, os compêndios pedagógicos, em geral, obedecem a uma organização padronizada: conceitos e regras de bom uso, seguidos de exemplos (retirados, em geral, da literatura canônica) e exercícios de identificação dos elementos gramaticais e correção de frases.

Embora não possamos negar a riqueza de grande parte das descrições gramaticais clássicas, o fato é que as gramáticas têm muitos limites, especialmente se levarmos em consideração as implicações dessa concepção de língua enquanto código para o ensino. Os alunos passam a crer que:
a) a língua é apenas aquela modalidade descrita na gramática;
b) a língua é um conjunto de palavras e frases descontextualizadas;
c) só se estuda a língua escrita;
d) qualquer uso diferente do prescrito é errado;
e) saber a língua é saber a nomenclatura com que se descreve a língua.

1. Salientamos, todavia, que as conclusões do estudo não param neste ponto. Os autores tecem, em seguida, considerações importantes sobre a relação educação versus sociedade e indicam alguns caminhos para a transformação da prática da avaliação. No momento, não aprofundaremos esta discussão. 
Dentro desse quadro, ganhou força (na escola, principalmente) a dicotomia "certo versus errado". O ensino de português se concentra no estabelecimento de formas linguísticas ideais, modelares, bem como na memorização da metalinguagem gramatical e, nessa perspectiva, a avaliação da aprendizagem se reduz à verificação da correção linguística como um conhecimento em si, ou da correção com que se emprega a nomenclatura em exaustivos exercícios de classificação (Suassuna, 1995). Eis aqui as muitas razões pelas quais se afirma que, na escola, não temos um sujeito que (se) diz, mas um aluno que repete/ devolve a palavra do professor (Geraldi, 1997).

Nosso propósito, no presente estudo, é problematizar a prática tradicional da avaliação no âmbito do ensino da língua portuguesa, tomando-a como uma ação discursiva multifacetada. Acreditamos que uma concepção ampliada de avaliação seria benéfica em dois níveis: (a) institucional, na medida em que ela funciona como indutora de políticas educacionais, visando à melhoria da qualidade do ensino, à garantia da aprendizagem e à socialização dos resultados do trabalho escolar; (b) epistemológico, na medida em que propicia uma nova abordagem do erro: ao invés de se considerá-lo como uma produção linguística diferente da estabelecida nas gramáticas normativas, ou mesmo como índice de fracasso do ensino e da aprendizagem da leitura/ escrita, deve-se entendê-lo como uma produção linguística resultante da relação do usuário com a situação de discurso e do seu nível de conhecimento da língua, gerado pelas situações de ensino e manifestado na forma de um conjunto de hipóteses lque podem ser inadequadas, incompletas, provisórias, etc.).

0 autor em cujo pensamento nos baseamos para a reconceptualização da avaliação é Walter Benjamin. No item 2 deste trabalho, vamos expor, de modo sinóptico, algumas de suas ideias sobre a narrativa que tiveram grande repercussão nos estudos sobre as práticas discursivas em geral. Trata-se, especificamente, do capítulo "O narrador - considerações sobre a obra de Nikolai Leskov", datado de 1936 e contido no livro Magia e técnica, arte e política - ensaios sobre literatura e história da cultura. Destacamos que não é o estudo sobre Nikolai Leskov o que mais nos interessa neste trabalho, e sim as teses de Benjamin sobre a narrativa enquanto discurso.

\section{A narrativa segundo Walter Benjamin}

Na obra em estudo, Walter Benjamin (1995) chama atenção para a importância de se intercambiarem experiências como algo próprio do gênero humano. No entanto, segundo ele, a experiência vem sendo desvalorizada e, por extensão, está em extinção a arte de narrar. Para Benjamin, a fonte de inspiração dos grandes narradores é exatamente a experiência que passa de pessoa a pessoa, e uma das 
marcas mais significativas da narrativa é o seu caráter de história oral contada pelo narrador anônimo.

A narrativa agrega saberes distantes no tempo e no espaço. Os grandes narradores eram ora o camponês - que acumulava informações do passado, em virtude de sua vida sedentária -, ora o marinheiro - que se apropriava de saberes de terras distantes, em virtude de sua vinculação com o comércio. A arte de narrar desses dois agentes sociais teria sido aperfeiçoada pelo artífice, pois "no sistema corporativo associava-se o saber das terras distantes, trazidos para casa pelos migrantes, com o saber do passado, recolhido pelo trabalhador sedentário." (Benjamin, 1995, p. 199).

Para Benjamin, a narrativa tem um caráter utilitário, no sentido de que traz em si ensinamentos morais, sugestões, práticas, provérbios ou normas de vida, advindos da sabedoria do narrador. 0 conselho, tecido na substância viva da experiência, consistiria não tanto em responder a uma pergunta, mas "fazer uma sugestão sobre a continuação de uma história que está sendo narrada." (Benjamin, 1995, p. 200). A sabedoria, por sua vez, é definida pelo autor como o lado épico da verdade; ela também está em extinção e a causa desse fenômeno da expulsão da narrativa da esfera do discurso vivo estaria na própria evolução do sistema de forças produtivas.

Um fator decisivo da decadência da narrativa no período moderno é o surgimento do romance, cuja difusão foi muito acelerada com a invenção da imprensa. 0 romance, portanto, está intimamente ligado ao livro, ao passo que a narrativa tem suas raízes na tradição oral, patrimônio da poesia épica. 0 narrador retira de sua própria experiência e/ou da dos outros aquilo que ele narra, incorporando as coisas narradas à experiência de seus ouvintes. Já o romancista atua como indivíduo isolado: "não pode mais falar exemplarmente sobre suas preocupações mais importantes (...); não recebe conselhos nem sabe dá-los." (Benjamin, 1995, p. 201).

Embora o romance remonte à antiguidade, seu florescimento - e o correspondente declínio da narrativa - tem estreita relação com a ascendência da burguesia, da qual a imprensa é um dos instrumentos mais importantes. Consolidado o capitalismo, ganhou destaque uma nova forma de comunicação: a informação. Esta influenciou decisivamente a forma épica e representa uma ameaça à narrativa e até mesmo ao próprio romance.

A informação, diz Benjamin (1995), é incompatível com a narrativa porque, se esta contém o saber que vem de longe lo longe espacial das terras estranhas ou 0 longe temporal contido na tradição), aquela tem como conteúdo acontecimentos próximos, sujeitos à verificação imediata. A arte narrativa evita o excesso de explicações; por isso, o leitor/ouvinte é livre para interpretar a história, e o episódio narrado tem uma amplitude inexistente na informação. Sobre o caráter aberto da narrativa e acabado da informação, afirma Benjamin: 
Cada manhã recebemos notícias de todo o mundo. E, no entanto, somos pobres em histórias surpreendentes. A razão é que os fatos já nos chegam acompanhados de explicações. Em outras palavras: quase nada do que acontece está a serviço da narrativa, e quase tudo está a serviço da informação. (Benjamin, 1995, p. 203).

Outro ponto relevante de diferença entre a narrativa e a informação está na sua durabilidade: a informação só tem valor quando nova está ligada a um momento e nele tem de se explicar; a narrativa, diferentemente, caracteriza-se por uma certa perenidade, pois conserva sua força e seu sentido por muito tempo.

A memorização das narrativas é facilitada pela sua concisão. 0 ouvinte, livre do detalhamento psicológico, grava as histórias narradas, assimila-as à sua experiência e reconta-as no futuro. Benjamin (1995) acha que esse trabalho de assimilação se dá em camadas muito profundas e exige um cada vez mais raro estado de distensão. A assimilação e a recontagem das histórias são fundamentais para a sobrevivência da narrativa: "Contar histórias sempre foi a arte de contá-las de novo, e ela se perde quando as histórias não são mais conservadas." (Benjamin, 1995, p. 205).

Benjamin considerava a narrativa uma forma artesanal de comunicação. Tendo florescido num meio de artesãos (no campo, no mar e na cidade), a narrativa não é mero relato, não está interessada em transmitir as informações como coisas em si; ela "mergulha a coisa na vida do narrador para em seguida retirá-la dele." (Benjamin, 1995, p. 205). Daí o autor ter feito uma comparação entre o narrador e o oleiro, na medida em que ambos imprimem sua marca em sua obra: a narrativa tem a marca do narrador, a argila do vaso tem a marca da mão do oleiro. A redução gradativa da comunicabilidade da experiência e da arte de narrar, característica do mundo moderno, explica-se porque o homem de hoje valoriza mais o que pode ser abreviado. Citando Valéry, Benjamin (1995) lembra a aversão cada vez maior ao trabalho prolongado.

Uma outra diferenciação presente nas reflexões do autor é aquela estabelecida entre o historiador e o cronista, entre quem escreve a história e quem a narra. No primeiro caso, temos alguém obrigado a explicar os episódios de um modo ou de outro. No segundo caso, o cronista se contentaria em representar os episódios como modelos da história do mundo. Desse modo, o cronista se preocuparia menos com o encadeamento exato de fatos determinados e mais com o modo de sua inserção no que Benjamin (1995, p. 209) chama de “fluxo insondável das coisas".

No estudo em discussão, Benjamin (1995) também tece considerações sobre a relação entre o narrador e o ouvinte, relação esta dominada pelo interesse em conservar o que foi narrado. Para o ouvinte, o importante seria assegurar a possibilidade de reprodução das histórias. A memória, de acordo com Benjamin, seria a mais épica de todas as faculdades. Na verdade, a reminiscência é que funda a cadeia da tradição que transmite os acontecimentos de geração a geração. Ela 
"tece a rede que em última instância todas as histórias constituem entre si." (p. 211). 0 que caracteriza a narrativa, em contraste com o romance, é a sua memória difusa, relativa a muitos fatos.

Ainda com relação à oposição narrativa $x$ romance, Benjamin afirma que 0 leitor do romance é solitário, mais do que qualquer outro leitor; nessa solidão, ele se apodera da matéria de sua leitura. 0 ouvinte da história, por seu turno, está sempre em companhia do narrador. 0 grande narrador tem raízes no povo, especialmente nas camadas artesanais. Do mesmo modo como essas camadas abrangem múltiplos artesãos, nos diferentes estágios de seu desenvolvimento econômico e técnico, são múltiplas as maneiras como os conceitos em que o acervo de experiências dessas camadas se manifesta. Daí Benjamin ter considerado que o narrador tem facilidade de se mover, para cima e para baixo, nos degraus da experiência.

0 narrador prototípico, primeiro e verdadeiro, seria o dos contos de fadas. Ele é ainda hoje o grande conselheiro das crianças. 0 conto de fada seria resultado de medidas tomadas pela humanidade para libertar-se do pesadelo mítico. Ele vem ensinando à humanidade que as forças do mundo mítico devem ser enfrentadas com astúcia e arrogância. Os ensinamentos dos contos de fadas forjariam o homem liberado, a criança feliz.

Mais uma vez citando Valéry, Benjamin alude à prática narrativa e diz que a narração, em seu aspecto sensível, não é apenas produto exclusivo da voz, mas também alma, olho, mão:

Na verdadeira narração, a mão intervém decisivamente, com seus gestos, aprendidos na experiência do trabalho, que sustentam de cem maneiras o fluxo do que é dito (...) A antiga coordenação da alma, do olhar e da mão (...) é típica do artesão, e é ela que encontramos sempre, onde quer que a arte de narrar seja praticada. (Benjamin, 1995, p. 221).

Após afirmar isso, o autor propõe ir mais longe, perguntando se a relação entre o narrador e sua matéria - a vida humana - não seria ela própria uma relação artesanal. Isso porque a tarefa do narrador é trabalhar a matéria-prima da experiência, transformando-a num "produto sólido, útil e único". (Benjamin, 1995, p. 221). E aqui o autor evoca os provérbios como sendo espécies de ideogramas da narrativa, ruínas de antigas narrativas nas quais a moral da história se enlaça com os acontecimentos.

0 narrador, portanto, poderia figurar ao lado dos mestres e dos sábios: ele sabe dar conselhos para muitos casos, pois pode recorrer ao acervo da vida - não apenas a sua própria experiência, como já assinalado, mas também à experiência alheia. 0 narrador assimila à sua substância o que sabe por ouvir dizer; tem o dom de contar a vida, e tem a dignidade de contá-la inteira. Benjamin arremata suas reflexões dizendo: "O narrador é a figura na qual o justo se encontra consigo 
mesmo." (Benjamin, 1995, p. 221).

\section{0 processo de ensino como narrativa; o professor como narrador}

0 pensamento de Walter Benjamin a respeito da narrativa e do narrador pode, sem dúvida, iluminar o debate contemporâneo sobre a educação em geral e sobre a avaliação em particular.

Nos tempos atuais, a educação tem sido vista como um processo discursivo complexo, que não pode ser explicado apenas em seu aspecto técnico. Hoje, não há como negar a diversidade de conhecimentos e saberes, bem como de seus modos de construção e circulação. Isso nos obriga a pensar a ação educativa à luz de novos paradigmas que levem em conta os múltiplos fluxos discursivos. A escola, com seu consagrado livro didático, não é o único espaço social onde germinam e circulam as informações, os significados e as narrativas. 0 professor não é mais aquele que transmite ao aluno um único discurso considerado legítimo, correto e oficial. Avaliar não se reduz apenas a cobrar de volta esse mesmo discurso.

É preciso abandonar as seguranças do mundo administrado, recolocar perguntas, reencontrar dúvidas, mobilizar inquietudes. É preciso tornar o mundo "legível", isto é, romper com os sistemas e práticas de educação que nos dão o mundo já interpretado, já configurado de uma certa maneira, já lido. É preciso reinventar os mecanismos de interpretação do mundo, criar novos modos de ver e ouvir o aluno, pois, se a educação é um processo em que se realiza o projeto que o educador tem do educando, é também o lugar em que o educando resiste a esse projeto e afirma sua alteridade. É preciso, ainda, inverter a direção do nosso olhar de professor, considerando que também o aluno nos olha e nos interpela. A possibilidade de depararmos com o novo está diretamente relacionada a esse olhar redirecionado, que leva em conta a pluralidade de ideias, respostas, formulações e conhecimentos produzidos nos processos de ensino (Larrosa, 2000).

A revisão paradigmática aqui proposta também inclui a aceitação do postulado da heterogeneidade do sujeito da educação. Assim, temos sujeitos em permanente deslocamento, tecendo, com palavras suas e outras, seus discursos². Essa intersecção de vozes significa que o lugar de onde o sujeito fala é também constituído de forma heterogênea: os alunos não escolhem de modo totalmente livre o que dizer dentro da escola; antes, suas posições são desenhadas por outras falas, que são, por sua vez, parte de sua memória. Por isso se pode afirmar que qualquer discurso resulta de um trabalho sobre outros discursos, que a palavra do enunciador é habitada por outras (Maingueneau, 1997). Além do mais, as posições não são definidas estática e definitivamente, uma para cada sujeito. Na verdade,

2. Essa seria, para Larrosa (2000), a forma de escapar à captura social da subjetividade, que nos obriga a ler-nos e escrever-nos de uma maneira fixa, dentro de um padrão estável. 
trata-se de lugares e posições instáveis, por entre os quais o mesmo sujeito se move. Temos, portanto, um sujeito disperso, atravessado por identidades imaginárias e ideologias; que assume uma pluralidade de formas, posições e funções; que, articulando discursos e visões de mundo, trabalha sobre e com a linguagem para constituir o seu próprio discurso.

No que diz respeito especificamente à avaliação, as teorias contemporâneas sugerem a criação de uma nova cultura avaliativa que ultrapasse o âmbito técnico e incorpore a dimensão ética implicada no ato de avaliar. Essa nova concepção de avaliação permitiria, primeiramente, pôr em questão a forma de atuação universalizante da escola laluno ideal, conteúdo fetichizado, avaliação padronizante), em franca contradição com o primado da heterogeneidade do discurso, da língua, dos sentidos e do próprio sujeito.

A avaliação - parte fundamental do processo ensino-aprendizagem - deve ser pensada no contexto de uma pedagogia democrática e pluralista. Ao invés de servir à exclusão social, pelos seus mecanismos típicos de classificação, a avaliação precisa ser reconfigurada como uma prática de efetiva reflexão, de modo a incluir as vozes dissonantes, historicamente silenciadas na escola.

Esteban (2000) propõe que o professor, no processo de avaliação, garanta a expressão, o reconhecimento e o fortalecimento dessas vozes dissonantes. Isso seria conseguido a partir da pergunta “por que não?", que se pode fazer diante das respostas erradas e destoantes de nossos alunos. Se a avaliação for, realmente, um trabalho de questionamento e investigação, conseguir-se-á negar a absolutização e a hegemonia de certos conhecimentos sobre outros, de certos discursos sobre outros. A tarefa do professor, para muito além de cobrar a devolução de uma informação congelada, acabada, é incorporar a experiência (sua e alheia) à experiência dos alunos, tornando o saber significativo para eles. Pode-se dizer que o professor insere os alunos no "fluxo insondável das coisas", assegurando-lhes a aprendizagem.

Nesse aspecto, Esteban (2000) se aproxima de Larrosa (2000): o olhar atento, a escuta refinada seriam constitutivos de um esforço de entender a lógica do outro. Nesse sentido, o erro não significa, necessariamente, ausência de conhecimentos; ele é indício do processo de construção cognitiva; traduz os trajetos dos alunos, que, muitas vezes, são diferentes daqueles esperados pelo professor; o erro oferece informações sobre o que se sabe e o que ainda não se sabe; permite formular novas perguntas. Aplica-se, neste caso, entre professor e aluno, a metáfora benjaminiana da relação interessada entre narrador e ouvinte: se há entre estes um interesse em conservar o que foi narrado, há entre aqueles um esforço de mútua compreensão em benefício da aprendizagem e do sucesso escolar.

Lembramos aqui a tese bakhtiniana de que o dialogismo, a relação com o outro, constitui o fundamento de toda discursividade (Bakhtin, 1986). Avaliar seria, portanto, antes de mais nada, dialogar com o texto do aluno, não apenas buscando os conteúdos (ou os erros e problemas) desse texto, mas posicionando-nos como 
o outro instituído pela interlocução, buscando os sentidos construídos no intervalo entre as posições enunciativas; em suma, refletindo sobre o que o aluno diz (Suassuna, 2006).

A visão da avaliação como narrativa também é importante por permitir lidar com o processo de produção de sentidos, e não apenas com o seu produto; por extensão, permite ao professor fazer avaliações mais descritivas e qualitativas das formulações dos alunos, pela inauguração de novas práticas de leitura, de novos mecanismos de escuta que levem em conta a relação entre o que é dito em um discurso e o que é dito em outro, o que é dito de um modo e o que é dito de outro; mecanismos que permitam também perceber o não dito naquilo que é dito. 0 professor seria, pois, o mestre, o sábio; aquele que, articulando conhecimentos, experiências, visões de mundo, dá conselhos. E essa articulação é tanto mais bem-sucedida quanto mais se dê numa perspectiva coletiva lem oposição ao leitor segregado do romance, conforme Benjamin). Na escola, o movimento de perguntar e responder é contínuo. Frente a cada formulação do aluno, podemos iniciar novos questionamentos, num processo permanente de construção/desconstrução/ reconstrução do conhecimento.

Em termos metodológicos, a concepção discursiva de avaliação contempla os gestos de interpretação postos no processo de ensino, que tanto podem ser do aluno lem seu trabalho contínuo de interpretação e reinterpretação do conhecimento), quanto do professor (em seu trabalho de compreensão da relação aluno-conhecimentol. Assim como o professor, o aluno é, ele também, um narrador, um articulador de visões de mundo.

Outro aspecto positivo dessa concepção é que o conceito de discurso contribuiu para abordagens mais amplas, não-redutoras, daquilo que sempre foi rechaçado como erro na escola, e que sempre desqualificou e reprovou o aluno (Pfeiffer, 1995). Por outro lado, podemos encontrar também aí algumas saídas para o dilema representado pela histórica oposição certo versus errado; não é por ser tomada discursivamente que qualquer produção de qualquer aluno pode ser considerada válida, legítima, correta. A singularidade do sujeito anda de par com sua constituição no interior das formações discursivas; portanto, não nos enganemos: a inscrição da língua e do sujeito na história implica também constrições simbólicas às quais os alunos estão sujeitos, e isso faz parte da produção/circulação do conhecimento (Orlandi, 1998a, 1998b).

Nesse aspecto, a relação narrativa versus memória, tal como pensada por Benjamin (1995), pode ajudar-nos a ver o valor e a importância do conhecimento historicamente acumulado - aí incluídas a língua padrão e a metalinguagem gramatical - na ampliação da vivência discursiva do aluno. Essa herança cultural deve ser encarada não como mera informação repassada pelo professor e reproduzida pelo aluno, mas como saber que vem de longe e com o qual se constitui e se pensa o saber de hoje. A escola é um espaço de reflexão e de alargamento da capacidade interpretativa do sujeito, lugar fundamental para a elaboração da 
experiência da autoria (passagem da função de sujeito enunciador para a de sujeito autor) na relação com a linguagem (Orlandi, 1988, 1998a).

Outro pressuposto a ser assumido é o da plurivalência do signo, pressuposto, aliás, que é correlato ao da heterogeneidade do sujeito (Bakhtin, 1986). Desse modo, os signos mobilizados pelo aluno são indicadores de seu nível de consciência e conhecimento, que resulta do ininterrupto processo de interação no qual ele internaliza a linguagem e se constitui como ser social (Geraldi, 1996).

Algo semelhante é sugerido por Batista (1997). O autor comenta que, no modelo de escola e de ensino ora vigente, a dispersão e a heterogeneidade do discurso tendem a ser reduzidas e homogeneizadas. Ele também destaca a natureza corretiva do ensino e sua influência nos resultados, uma vez que essa supervalorização do certo conforma a relação do aluno com a língua, levandoo a internalizar o olhar corretivo do professor. Diante disso, o autor destaca a importância de se tentar compreender o conhecimento que os alunos constroem na sua relação com a linguagem e com a atividade discursiva em sala de aula.

Esta, por seu turno, deve ser entendida como lugar de produção/circulação de sentidos. Caberia ao professor, então: (1) assumir-se como interlocutor dos alunos; (2) encarar a fala dos alunos como resultante de visões de mundo e saberes prévios; (3) aceitar a provisoriedade e o ineditismo do discurso; introduzir a casualidade como categoria na produção dos acontecimentos; (4) desestabilizar automatismos já estabelecidos em seus processos de leitura.

Essas atitudes avaliativas não devem ser entendidas nem como receita nem como objetificação do professor: para além disso, elas informam, ao nosso ver, um posicionamento coerente com a concepção de linguagem enquanto interação (e não código/estrutura). 0 espaço da sala de aula destina-se mais ao confronto e à reelaboração dos discursos aí produzidos e postos em circulação do que a mero trabalho que permita apenas a sua emergência. Por isso se pode afirmar que o professor é um "costurador" de experiências, e seu trabalho, o de um artífice (Suassuna, 2004).

Os textos dos alunos, em vez de corrigidos, "higienizados" (Jesus, 1995), hão de ser expandidos, juntamente com seu conhecimento em geral, e sobre a língua, particularmente ${ }^{3}$. Com relação a este último aspecto, diz Geraldi:

[...] a análise linguística a se praticar em sala de aula não é simples correção gramatical de textos face a um modelo de variedade e de suas convenções: mais do que isso, ela permite aos sujeitos retomar suas intuições sobre a linguagem, aumentá-las, torná-las conscientes e mesmo produzir, a partir delas, conhecimentos sobre a linguagem que o aluno usa e que outros usam. (Geraldi, 1995, p. 217).

3. Maingueneau (1997) lembra a dualidade radical da linguagem, a um só tempo integralmente formal e integralmente atravessada por embates subjetivos e sociais. 
Tal procedimento exige que nós, professores, favoreçamos o acesso aos le a produção dos) mais diferentes discursos, fazendo deles leituras ampliadas, redirecionando-os em função de nossas referências, entre elas as profissionais, as quais implicam, obrigatoriamente, recortes e intervenções de natureza didática ${ }^{4}$. A escola, sugere Orlandi (1998a), é lugar de se experimentar sentidos, de se expor os sujeitos às situações do dizer, com seus muitos efeitos. As formulações "erradas" dos alunos, em vez de nos assustarem ou causarem perplexidade e desalento, constituem-se em pistas e pontos de definição da atuação do professor. Em suma, a aula de português é um momento de produção/constituição de discursos e sujeitos, heterogêneos por definição. Se a escola (e, dentro dela, a avaliação) não é suficiente para isso, é, no entanto, radicalmente necessária.

4. Cf. Maingueneau (1997, p. 91): "0 texto não é um estoque inerte que basta segmentar para dele extrair uma interpretação, mas inscreve-se em uma cena enunciativa cujos lugares de produção e de interpretação estão atravessados por antecipações, reconstruções de suas respectivas imagens, imagens estas impostas pelos limites da formação discursiva." 


\section{Referências}

BAKHTIN, Mikhail. Marxismo e filosofia da linguagem. 3. ed., São Paulo: Hucitec, 1986.

BATISTA, Antônio Augusto Gomes. Aula de português - discurso e saberes escolares. São Paulo: Martins Fontes, 1997.

BENJAMIN, Walter. Magia e técnica, arte e política - ensaios sobre literatura e história da cultura. 7. ed., São Paulo: Brasiliense, 1995.

DEACON, Roger e PARKER, Ben. Educação como sujeição e como recusa. In: SILVA, Tomás Tadeu (org.). O sujeito da educação - estudos foucaultianos. 3. ed., Petrópolis: Vozes, 1994, p. 97-110.

ESTEBAN, Maria Teresa. A avaliação no cotidiano escolar. In: (Org.). Avaliação: uma prática em busca de novos sentidos. 2. ed., Rio de Janeiro: DP \& A, 2000, p. 7-28.

GERALDI, João Wanderley. Discurso e sujeito. In: Linguagem e ensino - exercícios de militância e divulgação. Campinas: ALB / Mercado de Letras, 1996, p. 9-23.

. Escrita, uso da escrita e avaliação. In: GERALDI, João Wanderley. (Org.). O texto na sala de aula. São Paulo: Ática, 1997, p. 127-131.

. Portos de passagem. 3. ed., São Paulo: Martins Fontes, 1995.

JESUS, Conceição Aparecida de. Reescrita: para além da higienização. 1995. Dissertação (Mestrado em Linguística) - Programa de Pós-graduação em Linguística. Universidade Estadual de Campinas/ Instituto de Estudos da Linguagem. 1995.

LARROSA, Jorge. Pedagogia profana: danças, piruetas e mascaradas. 3. ed., Belo Horizonte: Autêntica, 2000.

MAINGUENEAU, Dominique. Novas tendências em análise do discurso. 3. ed., Campinas: Pontes / Ed. da UNICAMP, 1997.

ORLANDI, Eni de Lourdes Puccinelli. A leitura proposta e os leitores possíveis. In: . (Org.). A leitura e os leitores. Campinas: Pontes, 1998a, p. 7-24. . Discurso e leitura. São Paulo: Cortez; Campinas: Editora da UNICAMP,

1988.

Identidade linguística escolar. In: SIGNORINI, Inês. (Org.). Língua(gem) e identidade - elementos para uma discussão no campo aplicado. Campinas: Mercado de Letras; São Paulo, FAPESP, 1998b, p. 203-212.

PFEIFFER, Cláudia. Que autor é este? 1995. Dissertação (Mestrado em Linguística). Programa de Pós-graduação em Linguística. Universidade Estadual de Campinas/ Instituto de Estudos da Linguagem, 1995.

SARMENTO, Diva Chaves. (Coord.). O discurso e a prática da avaliação na escola. Campinas: Pontes; Juiz de Fora: EDUFJF, 1997.

SUASSUNA, Lívia. A teoria sociointeracionista de Mikhail Bakhtin e suas implicações para a avaliação educacional. In: Ensaios de pedagogia da língua portuguesa. Recife, Ed. da UFPE, 2006, p. 205-220. 
Papirus, 1995.

. Ensino de língua portuguesa - uma abordagem pragmática. Campinas:

. Linguagem como discurso - implicações para as práticas de avaliação. 2004. Tese (Doutorado em Linguística). Programa de Pós-graduação em Linguística. Universidade Estadual de Campinas, Instituto de Estudos da Linguagem. 2004.

VEIGA-NETO, Alfredo José da. Foucault e a educação: outros estudos foucaultianos. In: SILVA, Tomás Tadeu (org.). O sujeito da educação: estudos foucaultianos. 3. ed., Petrópolis: Vozes, 1994, p. 225-246.

Recebido em junho de 2012

Aprovado em agosto de 2012

Lívia Suassuna é licenciada em Letras-Português pela UFPE, mestre em Língua Portuguesa pela PUC-SP e doutora em Linguística pela UNICAMP. Atualmente é professora adjunta da UFPE e membro do Conselho Editorial da revista Leitura teoria e prática. Últimas publicações: Avaliação e reescrita de textos escolares: a mediação do professor. In: Vanda Maria Elias. (Org.). Ensino de língua portuguesa - oralidade, escrita e leitura. São Paulo: Contexto, 2011, p. 119-134 e Ensino de análise linguística - situando a discussão. In: Alexsandro Silva, Ana Cláudia Pessoa e Ana Lima. (orgs.). Ensino de gramática - reflexões sobre a língua portuguesa na escola. Belo Horizonte: Autêntica, 2012, p. 11-28. Email: livia.suassunadufpe.br. 